\section{A community of practice for graduate students in health sciences}

\author{
Liquaa Wazni and Wendy Gifford \\ School of Nursing, Faculty of Health Sciences, University of Ottawa, Ottawa, Canada \\ Christina Cantin \\ School of Nursing, Faculty of Health Sciences, Queen's University, Kingston, \\ Canada, and \\ Barbara Davies \\ School of Nursing, Faculty of Health Sciences, University of Ottawa, Ottawa, Canada
}

\section{CoP for graduate students}

\begin{abstract}
Purpose - The aim of this study was to describe the experiences of graduate students who participated in the community of practice $(\mathrm{CoP})$ and identify areas for improvement to support academic success.

Design/methodology/approach - In total, 19 graduate students engaged in a $\mathrm{CoP}$ to facilitate social interactions, knowledge sharing and learning within a culture of scholarship. A descriptive qualitative research study was conducted using semistructured interviews with eight participants who had attended the CoP meeting.

Findings - All participants were from the School of Nursing and perceived the CoP to be beneficial, particularly international students who had challenges in adapting to new academic and social environments. Areas for improvement include creating a group structure that enhances belonging and learning.

Originality/value - This is the first $\mathrm{CoP}$ that was implemented at the Faculty of Health Sciences at the authors' university. It has been the authors' experience that a $\mathrm{CoP}$ can benefit graduate students through networking, knowledge sharing, social support and learning. The finding of this research will be used to inform a new $\mathrm{CoP}$ to address the needs of graduate students. The authors will be adapting the CoP to the current context that includes a virtual platform during the COVID-19 pandemic and will include content specific for international students.
\end{abstract}

Keywords Community of practice, Higher education, Graduate students, International students,

Social learning, Health sciences, Nursing

Paper type Research paper

\section{Background}

Many graduate students experience high levels of stress during their education, particularly if they are managing multiple priorities such as family and employment or are studying abroad

(C) Liquaa Wazni, Wendy Gifford, Christina Cantin and Barbara Davies. Published in Higher Education Evaluation and Development. Published by Emerald Publishing Limited. This article is published under the Creative Commons Attribution (CC BY 4.0) licence. Anyone may reproduce, distribute, translate and create derivative works of this article (for both commercial and non-commercial purposes), subject to full attribution to the original publication and authors. The full terms of this licence may be seen at http://creativecommons.org/licences/by/4.0/legalcode

The authors would like to thank all the graduate students who participated in the community of practice. The authors would also like to acknowledge Dr. Mary Ann Murray for her contributions to the $\mathrm{CoP}$ and provide a special acknowledgement to the authors' colleague Dr. Jennifer Kryworuchko, Associate Professor at the University of British Columbia School of Nursing, who passed away in October 2019.

Funding: This study was funded by the University of Ottawa Faculty of Health Sciences: Mission Satisfaction Fund.
Received 3 October 2020 Revised 6 February 2021 Accepted 17 March 2021 
HEED

15,2

(Brown et al., 2016; DeClou, 2016; Evans et al., 2018; Ickes et al., 2015). The cumulative effects of academic demands, financial concerns and new social relations can cause stress and exhaustion that negatively affects students' physical and psychosocial well-being (Evans et al., 2018; Mazurek Melnyk et al., 2016). A study of 93 graduate students in health sciences in the United States revealed that $41 \%$ had depressive symptoms, $28 \%$ experienced anxiety and $4 \%$ reported suicidal ideation (Mazurek Melnyk et al., 2016). According to deChambeau (2014), "the practice of becoming an accomplished and successful student, who is able to develop scholarly abilities and deepen disciplinary understanding, experience personal growth and achievement, while at the same time maintaining a healthy school-work-life balance is a non-trivial exercise" (p. 16). Faculties are encouraged to implement networking opportunities for graduate students to build relationships, receive support and interact with faculty and nonfaculty members to develop their skills and competencies (DeClou, 2016; Ray et al., 2019).

Palmer (2002) noted that "academic culture is infamous for fragmentation, isolation and competitive individualism, with no sense of being part of a community" (p. 179). Lack of peer interaction and gaps in communication and collaboration continue to be one of the most concerning problems among graduate students (Ray et al., 2019). Graduate students often feel isolated and socially disconnected during their graduate student tenure as they are often required to work on their own (Ray et al., 2019). These feelings can be particularly strong for students who have travelled to attend school (Culver and Bertram, 2017; Ray et al., 2019). Social isolation and lack of meaningful social connection is shown to increase attrition of graduate students (Blanchard, 2018; Peltonen et al., 2017; Rigler et al., 2017). In addition, students who feel unsupported are at higher risk of negative social, health and educational retention outcomes (Cepanec et al., 2016). According to DeClou (2016), attrition influences work opportunities and income of students who leave the program. It also results in lost investment in students for institutions and loss of productivity and wealth for the society. On the other hand, institutional and social supports can positively influence the emotional wellbeing of graduate students and thereby increase academic success and retention (DeClou, 2016). Furthermore, the author suggested that interventions aimed at supporting graduate students should focus on facilitating a sense of support, belonging, engagement and learning. Creating enabling learning spaces in which students colead and engage in reciprocal learning and power sharing was recommended to help counteract isolation and develop expertise among graduate students (DeClou, 2016; Ray et al., 2019).

A community of practice $(\mathrm{CoP})$ is a group of people "who share a concern, a set of problems or a passion about a topic and who deepen their knowledge and expertise in this area by interacting on an ongoing basis" (Wenger et al., 2002, p. 4). CoPs reflect the social nature of learning and provide an environment for people to interact and engage with colleagues and people with different levels of expertise on a topic, thereby increasing a sense of social integration and learning (Li et al., 2009). By creating tacit knowledge that is sometimes not captured by formal learning, CoPs are believed to foster the social nature of human learning (Wenger-Trayner and Wenger-Trayner, 2015). In the past decade, CoPs have gained popularity for their potential benefits for social learning and knowledge development. Various sectors such as business, education and professional associations are now focusing on improving their performance through CoP. CoPs come in many forms (formal or informal; local or global; in-person or virtual and small or large group) and can be established through organizations or develop spontaneously (Wenger-Trayner and Wenger-Trayner, 2015).

CoPs are informed by social cognitive theory that focuses on cognitive process of learning in a social context (McDonald and Cater-Steel, 2016; Wenger-Trayner and Wenger-Trayner, 2015). Albert Bandura first proposed social cognitive theory in 1986 in response to Watson's behaviorism, which suggested that all leanings are associated with reward and punishment. The theory moved beyond behaviorism to consider environmental and cognitive factors that shape human learning (Bandura, 1999). It suggested that learning occurs within a social 
context in which individuals learn and develop cognitive functioning from each other by observation, imitation, and modeling (Bandura, 1999). Social cognitive theory presented observational learning and triadic reciprocal determinism as key concepts (Bandura, 1999). Observational learning refers to learning by direct observation and interactions with others in a social context. Paying attention, retaining and redoing are important processes in observational learning and require personal motivation and self-efficacy (Bandura, 1999). Intrinsic reinforcements, such as feelings of accomplishment and satisfaction, are forms of internal rewards that play a major role in learning (Bandura, 1999).

The concept of triadic reciprocal determinism represents the dynamic interaction between three factors that affect learning: personal factors, behaviors and the environment. Personal factors refer to internal aspects of an individual that include preconceptions, values, goals, motivations and cognitive capabilities (Bandura, 1999). Personal factors have a role in how challenges are approached, goals are achieved and tasks are completed (Bandura, 1999). Behavioral factors refer to actions that are directed toward progress of goals, motivation and learning, which eventually became self-regulated based on the response individuals receive from their environment (Bandura, 1999). Environmental factors represent the social context in which the behaviors occurs. The reciprocal relationship between these three factors indicates that an individual's behaviors are both affected by and affect personal factors and the social environment (Bandura, 1999). While internal factors such as motivation and goals can influence an individuals' behavior, external factors such as interactions within certain environments also trigger motivation and lead to certain behaviors such as learning.

$\mathrm{CoPs}$ are based on social cognitive theory as they are built on concepts of observational learning (learning from each other) and learning that is accomplished through partnerships around practices with shared interests, goals and motivations. Learning takes place through participation in social practices and informal contexts. Unlike formal learning in which instructors define goals and objectives, $\mathrm{CoP}$ members have opportunities to determine goals, share and receive knowledge and peer-support and learn from each other. In addition, the performances of members are not formally evaluated in a $\mathrm{CoP}$ because learning is believed to be an internal process, which may, or may not, result in change.

Domain, community and practice are three distinctive elements that characterize a CoP. Development of these three elements in parallel is what cultivates a $\mathrm{CoP}$ and differentiates it from other types of networking (Wenger-Trayner and Wenger-Trayner, 2015). Becoming a member of CoP implies a commitment to a shared domain of interest, knowledge, competence or expertise (Wenger-Trayner and Wenger-Trayner, 2015). Shared domain of interest is the source of identification, connection and commitment for the members as they organize themselves to negotiate a practice with which to share and identify. As a community, members join this network to build relationships, engage in discussions, share their knowledge and experiences and learn from each other (Wenger-Trayner and Wenger-Trayner, 2015).

Engaging and exchanging information through a joint enterprise with a shared repertoire of resources that include experiences and updates on tools, stories, templates and strategies is believed to increase a sense of belonging and satisfaction, facilitate progress and enhance knowledge and expertise for the members (Iverson, 2010). When members of a successful CoP come together, the process of exchanging ideas and thinking together has been described as a transpersonal knowing process through which tacit knowledge is "shared" indirectly and that essentially "brings CoPs to life" (Pyrko et al., 2017, p. 391). These are a few of the direct benefits of a $\mathrm{CoP}$.

In the context of higher education with its associated demands, CoPs are shown to provide personal as well as professional development that is grounded in members' needs (Reaburn and McDonald, 2017). CoPs are encouraged to be implemented in higher education to help engage and empower students, increase socialization and sense of belonging and create a space for problem-solving and voicing concerns (MacGillivray, 2017). Implementing a CoP 
HEED

15,2

138

with graduate students and professors from humanities and social science in a large Canadian university, Culver and Bertram (2017) suggest CoPs in higher education can help create innovation, improve progress and enrich learning by sharing and exchanging resources and ideas. The authors recommend $\mathrm{CoPs}$ for graduate students in more disciplines, recognizing that further research is required.

As faculty members, graduate students and alumni from a large Canadian university, we established a CoP for graduate students at the Faculty of Health Sciences to enhance academic success through social engagement, dialogue, networking and peer support. In this paper, we describe findings from a qualitative study that explored the experiences of graduate students who had participated in the CoP. Specifically, we addressed the following research questions: (1) what aspects of the CoP meetings were most useful and why? and (2) how can a $\mathrm{CoP}$ better facilitate social interactions, knowledge sharing, knowledge creation and identity for graduate students. For this study, graduate students were individuals who had earned a bachelor's degree and were pursuing education at the Masters or $\mathrm{PhD}$ level.

\section{Methods \\ CoP design}

We established a graduate student $\mathrm{CoP}$ in response to a request for proposals to support the student experience in the Faculty of Health Sciences at a large Canadian university. Masters and doctorate degrees were offered in the School of Human Kinetics, Nursing and Rehabilitation with over 675 graduate students across two campuses. Schools of Nursing and Rehabilitation Sciences located at one campus and made up $67 \%$ of all Faculty of Health Sciences graduate students (approximately 400 Masters and $30 \mathrm{PhD}$ ), with the majority completing a course-based Masters program.

Monthly CoP meetings were offered on-site at one campus where the Schools of Nursing and Rehabilitation Sciences were located. A toll-free teleconference line was available for those who were not able to attend on-site. To advertise, $\mathrm{CoP}$ posters were displayed around both campuses, and an email was sent to all faculty members and graduate students in health sciences to announce this new group. Although other events such as monthly research seminars and presentations from professors and students were taking place for graduate students, these events were not specifically focussed on graduate student needs, social support or learning. The $\mathrm{CoP}$ provided a forum for students to engage in dialogue, debate, networking and peer support with people at different stages in their graduate degree or postgraduation career. A faculty member and hospital administrator, who had recently completed their doctoral degrees in nursing, co-led the program. Lunch was provided for those attending on-site.

Members of the $\mathrm{CoP}$ were invited to share their contact information (email/phone) through an electronic distribution list in addition to any personal information they wished to share such as where they were from, their program of study, research interests and clinical background. Each $\mathrm{CoP}$ session began with an informal round table introduction and discussion followed by a focussed talk by a guest or group leader about a specific topic related to graduate studies. Topics for discussions were chosen based on suggestion by the $\mathrm{CoP}$ members. Examples of topics included paper-based thesis format versus traditional monograph style, preparation for comprehensive exams, use of reference management software and research analysis software, and research topics (see Table 1 for a description of the key elements of the $\mathrm{CoP}$ ).

\section{Setting and sample}

In total, 19 graduate students $(\mathrm{PhD}=14$; thesis based Masters $=5)$ participated over the academic year, with attendance at each $\mathrm{CoP}$ meeting ranging from two to 17 (mean $=8.4$; 
Domain

(1) Facilitated social interactions, knowledge sharing, knowledge creation and identity for graduate students

Community

(1) Members included graduate students at the faculty of health sciences within a large Canadian university

(2) Facilitators were PhD prepared members: one faculty member employed by the university and one hospital administrator

Practice

(1) Provided a forum for graduate students, faculty members and alumni to engage in dialogue, debate, networking and peer support with people at different stages in their graduate or post-graduation career

(2) Monthly one-hour seminars, with topics for discussions based on suggestion by the CoP members (e.g. paper-based thesis format versus traditional monograph style, preparation for comprehensive exams, use of reference management software and research analysis software, and research topics)

(3) Communication and sharing of documents among members via email

(4) Lunch provided at each seminar

\section{CoP for graduate students}

$\mathrm{SD}=4.2$ ). All participants were from the School of Nursing except one from Rehabilitation; all but one attended in person. At the end of the academic year, $\mathrm{CoP}$ participants were invited to complete a regular evaluation at the final $\mathrm{CoP}$ session or electronically for everyone who had attended. In total, 11 participants $(58 \%)$ completed the evaluation, rating $\mathrm{CoP}$ meetings as extremely or somewhat useful with a mean rating 3.7 on a four-point Likert scale. Although funding and resources for the $\mathrm{CoP}$ ended after one academic year, all participants reported that they would encourage graduate students to attend $\mathrm{CoP}$ meetings in the future. Our research team wanted to better understand the elements that were perceived as useful and to learn in more depth about recommendations for the future. To explore graduate students' experiences of the usefulness $\mathrm{CoP}$ program, a descriptive qualitative study was conducted with a purposeful sample of CoP participants. All graduate students who had attended at least one $\mathrm{CoP}$ meeting were invited to participate via email. In total, eight graduate students participated in the interviews. All were graduate students from the School of Nursing at the Masters $(n=3)$ or $\mathrm{PhD}(n=5)$ levels, and three were international students.

\section{Data collection}

Interviews were conducted in-person or by telephone by a research assistant who had attended the $\mathrm{CoP}$ meetings as a graduate student prior to being hired as a research assistant for the study (CC). A semistructured interview guide was developed to guide the interviews based on four characteristics of a CoP described by Li et al. (2009): "social interaction", "knowledge sharing", "knowledge creation" and "identity building". During interviews, participants were asked about their experiences with the CoP program in relation to the four $\mathrm{CoP}$ characteristics, supports and barriers to participation and suggestions for improvements of future CoPs. Example of questions include thinking about your experience as a graduate student, what could be done in $\mathrm{CoP}$ meetings for the academic school years to facilitate and enhance social interaction, knowledge sharing, knowledge creation and identity building for graduate students? What recommendations do you have for structured discussions in the future $\mathrm{CoP}$ meetings, if any? How can the CoP meetings be supported and enhanced for graduate students in the Faculty of Health Sciences? Research ethics board approval was obtained from the university in which the $\mathrm{CoP}$ took place. Participation was voluntary, and informed consent was obtained from all participants prior to data collection. Pseudonyms were used for anonymity and confidentiality.

Data analysis. Interviews were audio-recorded, transcribed verbatim and entered into a qualitative software program (NVivo 10). Interview data were analyzed and coded using a descriptive content analysis approach (Sandelowski, 2000). A coding structure was 
HEED

15,2

140

iteratively developed based on participant responses to the questions in the interview guide. Relevant passages were inductively coded using words of participants, and recurring ideas were organized and grouped into response categories, displayed in coding matrices to identify patterns and regularities and condensed into descriptive themes (Sandelowski, 2000). The coding structure and themes were reviewed by a convenience sample of participants (member checking) and the research team, and discrepancies in coding and interpretations were resolved through group discussions between the study investigators.

\section{Results}

The results will be described in three sections: useful aspects of the $\mathrm{CoP}$, barriers and facilitators to participation and areas to improve social interactions and knowledge sharing for graduate students.

\section{Useful aspects of a graduate student $\mathrm{CoP}$}

The useful aspects of the $\mathrm{CoP}$ will be described according to the four characteristics of a $\mathrm{CoP}$ as outlined/identified by Li et al. (2009): "social interaction", "knowledge sharing", "knowledge creation" and "identity building".

\section{Social interaction and identity building}

Participants discussed feelings of social isolation and disconnection from their peers during their graduate school tenure, particularly students who had completed their course work and no longer attended classes but were working on their thesis. As one participant explained,

... now that I'm not doing the course works, like it's very isolating now I find. Now I do not see anybody from my class. If I'm at the university I might see some other people here and there, but you know, it's not the same. If anything I mean I think the people that are doing their courses have lesser need for this Community of Practice than the people that are just out doing their research, I think. (Participant 2)

The feelings of isolation were particularly strong among international students who "did not have a solid base of friends or family here [in Canada]" (Participant 2). Even participants who were from the local community considered social isolation a concern: "It's isolating. I have to say, I'm local, married with kids, I really feel for those people who are from out of town or out of country" (Participant 1). Local participants reported seeing international students "really having a hard time and feeling really down" (Participant 2). All international students reported feeling socially isolated and struggling with differences in the culture, language, climate and academic environment:

So, I just want to say that the challenges one has as an international student is in amongst so much, and you find out that being an international student, you come from a different culture to another cultural setting; you have a lot of challenges, language, weather, academic environment. I mean to know even the geographic of the area, socialization even with the educational, I do not know how one can put it that. (Participant 4)

Being able to establish connections and socialize with other graduate students was a factor in attracting graduate students to participate in the $\mathrm{CoP}$. As one student expressed,

So it's not an academic type of support but I think it enhances that social interaction of graduate students, so you have a common experience as a graduate student but you're kind of getting that added support and more of that friendship, you kind of can dive a little bit deeper when you have these ongoing opportunities to interact. (Participant 5)

However, the socialization aspect of the $\mathrm{CoP}$ was especially important for international students: "CoP meeting not only to share the information but to meet the people, especially 
you know I'm here alone, I do not have family here in Canada, so if I meet friends seems like, oh I have somebody around me" (Participant 3). One of the international students reported that socialization was the main reason for attending $\mathrm{CoP}$ :

The first reason I attended that meeting was to have a network of social connections with some of the students so that I would have somebody I could talk to about, partly with some of the challenges I was facing. That was the reason.

It was really good to have such opportunity when I came in newly as an international student. Inever knew many people and it was an opportunity to interact with my colleagues. And I thought, well I felt that forum would provide an opportunity to socialize with my colleagues and have some support with my academic. (Participant 4)

$\mathrm{CoP}$ was a place for participants to connect, establish relationships and receive support. One international student explained this as follows:

They make the place comfortable and provided a forum that I could fit. They provided a forum that I felt as though and I felt like I have some people I can rely on because as an international student, you just felt very isolated, very lonely and no people. So I felt the fact that meeting them, the way they opened up, the way they called me, invited me and they found a way for me to speak was such a good one and I learned to appreciate them for that. (Participant 4)

Participants reported that they could not achieve the support, comfort and sense of belonging they needed through their academic experience. They spoke about participating in the CoP because of a need to socialize with other graduate students and build a network of colleagues to share challenges and concerns and learn from others. One student commented, "I remember being excited to kind of come to campus and just to be around other graduate students" (Participant 5). Involvement in the program created a sense of engagement, belonging, and connectedness for many of the students, "It [graduate school] is isolating and so that was the first time that I felt like I belonged to something bigger" (Participant 1).

While many participants experienced social support during the CoP meetings, some did not feel it extended outside of the monthly forum:

I do not think there was a whole lot of interaction aside from the one hour that we were sitting there around the table. . .that was the only interaction I felt I got because outside that meeting, there was no interaction with anybody. (Participant 7)

Another student explained a failed attempt to connect with students outside the meeting:

The students I tried to phone and to send emails to asking some things, I find out that either they were overwhelmed with their own academic studies or they themselves did not have the time to support or did not feel it was necessary to support others. (Participant 4)

While most local participants appreciated the socialization part of the $\mathrm{CoP}$, some were more interested in knowledge development suggesting that less social interaction can help focus on the knowledge sharing and knowledge development; "So I think there could have been more that would been gotten out of the meeting from the knowledge sharing and the identity building if some of the social interaction was maybe less" (Participant 2). On the other hand, all international students appreciated the socialization, as well as the knowledge development and sharing aspect of $\mathrm{CoP}$ :

I would like to say thank you so much for this $\mathrm{CoP}$ meeting. This is really important for me. For some reason the first. . .Because I have said that we gather information, we share information, we ask question. The second one, for international student especially, time to meet our friend because we do 
HEED

15,2 not have... Especially we do not have family here. Time to meet people, time to see, and then we do not feel lonely. Loneliness will disappear. (Participant 3)

A number of participants expressed that a $\mathrm{CoP}$ was useful to build graduate student identity and understand "how to be a graduate student" (Participant 5), including expectations beyond course requirements and challenges others experienced along the way. The $\mathrm{CoP}$ was perceived to be useful as a forum to discuss different options and opportunities for future careers once graduate school was over.

\section{Knowledge sharing and knowledge creation}

Participants appreciated being able to ask questions and brainstorm ideas in relation to their studies, share experiences through various phases of the graduate program, articulate needs and gain awareness of available resources. One student expressed his/her appreciation for having the opportunity to problem solve with other students in the $\mathrm{CoP}$ as a way of sharing and creating knowledge: "I had the opportunity to ask questions from other students or one of the invites about resources... and she suggested emailing one or two people at the [organization]... that was relevant" (Participant 7). International students found the knowledge creation and sharing information and resources important because they lacked knowledge about many things in Canada, the country where they were studying: "information for you is perhaps second nature; for international student it is absolutely new, they [local students] do not have an idea" (Participant 3). A local student described the needs of international students as follows:

I think when we talk about the international students, a lot of support with writing skills would be important. Maybe the, I think they do not always understand either the Canadian healthcare reality, so how to help them to get their heads around that. Well there's life in Canada in terms of [the cold weather] and boots, and then there's thinking about doing nursing research in Canada. (Participant 2)

International students confirmed these challenges and reported their needs for information to support them in their graduate student journey:

I experienced it (. . .) you have a lot of challenges. Even the lecturer the way they speak, their accents (...) as an international student you have to listen so attentively. The language barrier is really a challenge. How academic instructions are given. It really gets challenging to an international student. (Participant 4)

$\mathrm{CoP}$ provided an opportunity for international students "to hear from the other people" (Participant 3) and "learn about the Canadian context" (Participant 8), especially from local students. One of the international students explained: "in this meeting we gather together, we get information from other friends, and then we can ask if we have something [we] want to know. So this is really important for us" (Participant 3). They found the CoP beneficial because "the program related to everything, everything in this university, for me as an international student, this is really important"(Participant 3).

Participants found it useful to interact and share information with graduate students at both masters and $\mathrm{PhD}$ levels, "I think it was valuable, like different layers of experience" (Participant 5). They reported that knowledge sharing within the sessions helped them learn "... about the program, about the school, about the courses, about. . .everything" (Participant 3). They also considered the knowledge that was created as result of $\mathrm{CoP}$ was mostly related to the academic work. Some participants found the informal presentations as a learning opportunity that informed their practice as a graduate student:

...knowledge creation piece is more what happened amongst us as students when it was brought into kind of the classroom context, or the learning context. . there was a couple of presentations that 
were good, and it was done informally... presentation on the different types of thesis, you know the manuscript versus the [monograph]. (Participant 2)

Participants also reported that they were able to get feedback from members in relation to their assignments and projects, and as a result of participating in $\mathrm{CoP}$, they were able to learn how to accomplish certain tasks (formatting, scholarly writing, etc). Some participants considered brainstorming academic assignments and receiving informative feedback and direction helped them advance in their academic work. This was particularly important for international students who were adapting to a new educational system. $\mathrm{CoP}$ provided a space for them to share their experiences from their home country, compare their experiences in both contexts,and receive feedback: "for me, I share my information, especially my questions. So they give me input, they give me feedback. I share my experience in [name of their country], so I compare in this meeting" (Participant 4). One of the international students reported that without the $\mathrm{CoP}$, they would not have learned and gained access to some important information and resources:

Without Community of Practice [it is] not easy for me. . . not easy for me because, you know, I do not know where I have to ask, with whom I have to talk, and then except for my Supervisor... for the friends it's not easy, they are busy, [but] in the community [of practice] meeting, there is the facilitation [for] us. (Participant 3)

Knowledge creation was reported to vary "depending on where you were at with your program or where you were in terms of $[\mathrm{PhD}]$ versus Masters, in-course work versus working on your research, or those kinds of things" (Participant 2). Students also described the participatory environment welcoming, which enabled them to network and exchange valuable information that helped them navigate their graduate experience: "I think people were really good to share their experiences... so different aspects, giving helpful hints and suggestions... and we did have a couple of those guest speakers and everyone listened very carefully." (Participant 5)

Having researchers or professionals from the community with expertise on specific topics come to meetings was considered a useful way to share knowledge: "maybe we talk about grounded theory or we will talk about mixed method, who is the expert in this area, so we invite them in our CoP meeting" (Participant 3). While most participants considered learning from others' experiences and ideas an important part of knowledge development, some considered formal presentation more important for knowledge creation and personal experiences, ideas and strategies of limited value since each person's experience can be different. As one participant explained:

One of the things I'm learning is, like you can hear about somebody else's personal experience and think it might help you, but in the end your experience winds up being very different and so in retrospect it's not really helpful, you know, to help prepare you for something. I just, I think about our Comps [comprehensive exam], like we had a presentation from some previous students that came to our class. . .about their experience with the Comps and. . . So I went into it with a certain mindset and it wind up being very, very, very, very different. So you kind of almost have to be cautious of the personal experience kinds of presentations. (Participant 2)

\section{Facilitators and barriers to participation}

Facilitators and barriers to participation among international and local students were similar. Participants reported three factors that facilitated their participation in the CoP: scheduling of the meetings after class, receiving e-mails or announcements about the program and having reminders to attend. Email announcements and monthly reminders were considered helpful, with word-of-mouth by faculty and friends the most effective way to encourage participation. One student explained that "Not only because [of] email, [but] friends who will come always 
HEED

15,2

144

call me [saying], 'come, come, it is important', especially some of my friends from international students" (Participant 3). While some participants liked having an informal agenda that responded to the needs of the group, others expressed their preference for a structured schedule with topics and presentations to facilitate discussions.

Scheduling conflicts were the main barrier for students to attend sessions. Other barriers included lack of interest in the scheduled topics, informal structure of meetings, meeting location, competing priorities (such as employment or school assignments) and uncertainty about how the program would meet participants' needs. Some students also expressed frustration in the way group members shared information with each other rather than with the group as a whole:

I noticed there was a lot of one-on-one talk, you know, like someone would come in and they may be closer to one person and not to the other one, and they would, you know, disclose, "Okay, I know of this. . . editor" for example, "We'll talk after the group." Well then why did you come? You know what I mean, like, if you have information about editors, good editors, or good, you know, just experience like that about publication, and you could share it to the group and not one on one. . . which I thought that was disgusting so I did not go for the rest of the meetings. (Participant 7)

\section{Areas to improve social interactions and knowledge sharing for graduate students}

Most participants preferred a forum that was open to new students' memberships at any time while a few participants thought new student members should only join at designated times to help form a group identity. A combination of both formal and informal discussions were seen to be the most useful to allow an organic exploration of specific topics. While participants understood the need to have a forum to vent, when one student took over the conversation some participants found it difficult to contribute. Also when students came to the meetings expecting a particular topic to be covered in the more structured part of the meeting, and it was not, either due to too much informal conversation or poor organization, it impacted their attendance at future meetings. Some students indicated that sometimes the sharing aspect dominated most of the meeting, sometimes with one student discussing a particular issue at length.

While areas to improve social interactions and knowledge sharing were similar between local and international students, international students felt they would benefit from having specific meetings to address their unique needs, running it more frequently at the beginning of each academic year to facilitate orientation and social connections. One of the international students suggested, "linkages between professors and students, early upon arrival, [information on university's] website not clear. One-to-one connection initially, but can then funnel into larger CoP" (Participant 8). The needs of learning for international students were perceived as unique, with one local student suggesting that international students would benefit from having a separate group:

The international students, they almost like need their own separate group or kind of like orientation to again these things that people just know that you cannot assume someone new to the country would know. Like even information about like the healthcare system or, you know, navigating. (Participant 5)

Further topics of interest to international students included learning about the Canadian healthcare system and the role of different healthcare professionals, the weather and how to be prepared for this and academic expectations. As explained by one of the international students, "international students do not know how to approach the situation and are afraid of the conflict and potential ramifications; [different university/college expectations] need to make this clear" (Participant 8). Participants discussed the benefits of having materials and resources for $\mathrm{CoP}$ members to enhance the graduate student experiences such as lists of 
university services, city maps and useful software programs. In response to what could be provided to improve the $\mathrm{CoP}$ for graduate students, one student explained that:

I just learned the other day that there's a grad lounge. Yeah, I did not know about that until three and a half years into my program. And I also just found out about the ability to get parking passes on the weekends for [the university], so this applies to local and not local. Like these kinds of things. What's different about being a grad student, what kind of facilities and maybe library privileges, this kind of thing, what is out there. (Participant 1)

Other suggestions included having an online forum for discussions and resources for writings grants and scholarship applications. Opportunities for new international graduate students to be mentored by established graduate students to navigate the university and their program of study were also recommended. To build a culture of scholarship within a graduate school community, participants recommended having a designated space to help students adjust to "graduate student life" and increase their abilities to interact with other graduate students.

\section{Discussion}

In our study, participants engaged in a $\mathrm{CoP}$ with other graduate students, graduate school alumni and faculty members as a mechanism to facilitate social interactions, knowledge sharing and learning within a culture of scholarship. Faculty, clinicians and graduate students were brought together as coparticipants to foster professional collaboration consistent with a CoP. All study participants expressed a need to build social networks to support their academic success while in graduate school, particularly once course work was completed and fewer opportunities existed for interacting socially at the university. While educational seminars provide a similar foundation in sharing, students are evaluated on their performance; Cops are different given the focus is on social relationships between experts and learners (Culver and Bertram, 2017).

Researchers indicate that more graduate students rely more on social support as a coping mechanism when compared to undergraduate students (Ickes et al., 2015; Ray et al., 2019). Our participants described the $\mathrm{CoP}$ as useful for discussing student issues, gaining support, solving problems and socializing. Cater-Steel et al. (2017) explored the usefulness of a $\mathrm{CoP}$ for supervisors of graduate students in all faculties at the University of Southern Queensland, Australia. The $\mathrm{CoP}$, which began in 2009, was formed to provide a formal social network to encourage education and promote best practice approaches to research supervision (CaterSteel et al., 2017). The study reported that by the end of 2015, they held a total of 47 meetings and 1,214 attendees. Meetings focused on both administrative and academic knowledge and competencies of supervisors with a wide range of topics such as research strategies, ethics approval processes, workplace safety for students, student-supervisor relationships, development of proposal and candidature. The study found $\mathrm{CoP}$ useful for sharing practices, networking and developing competencies (Cater-Steel et al., 2017). The study also reported that participating in $\mathrm{CoP}$ increased supervisors' confidence in their abilities and provided them with ways to improve their skills. The usefulness of the $\mathrm{CoP}$ was reported to be in-line with members' motivation for participation including professional development, sharing knowledge and becoming a member of a community.

In our study, the need for socialization was particularly strong for the three international students who had unique needs of adapting to a foreign learning environment. While our sample was small, research indicates that international graduate students are at additional risk for stress and its associated physical and psychological symptoms as they encounter broader challenges related to transitioning and adjusting to a new cultural, social and pedagogical environment (Wu et al., 2015; Ray et al., 2019). In particular, the reported 
HEED

15,2

146

challenges include learning the academic culture, developing new social supports and establishing new friendships are long-term challenges with language barriers, financial hardships, discrimination and loss of identity (Karkar-Esperat, 2018; Ray et al., 2019; Merola et al., 2019).

Our findings are consistent with studies that also reported that international students needed more support on arrival to their destination country, with barriers to healthy adjustments related to social interactions, transportation and discrimination (Ammigan and Jones, 2018; Merola et al., 2019; Ray et al., 2019, Arkoudis et al., 2018). Our findings add to the growing literature that suggests international graduate students require tailored support that is specific to their country of origin and study. The twofold increase in the proportion of international university students in Canada over the last decade underscores the importance of this finding, particularly with the trend of increasing international student enrollment. The number of international students in Canada increased by $68 \%$ between 2014 and 2018 (Government of Canada, 2020). In 2013-2014, international students comprised 17\% of all Masters students and $29 \%$ of all $\mathrm{PhD}$ students in Canada (Statistics Canada, 2016). Providing a peer mentor for international students was suggested by our participants to address questions and concerns, connect them to resources and help them build social networks can help their integration effort and academic success.

Providing a setting where students get the opportunity to integrate and apply their knowledge is essential for knowledge development (Culver and Bertram, 2017) and is a core component of a $\mathrm{CoP}$. This study demonstrated that students wanted experiences beyond their academic classroom teachings, and the $\mathrm{CoP}$ was a venue that created a sense of support and learning. Reading, discussing and reflecting on their academic work and related topic enhanced comprehension, understanding and learning of the participants. Participants also conveyed that the $\mathrm{CoP}$ was useful to build a graduate student identity. Building an identity is a cognitive process of constructing and expressing an image along with values, duties and boundaries (Davis, 2006). According to Culver and Bertram (2017), engaging in social learning spaces such as a $\mathrm{CoP}$ in which negotiations focus on a specific domain of interest can help students develop a sense of identity and competence in their practice. Fenge (2012) who studied the role of group supervision in improving the doctoral journey also indicated that learning spaces that are supported by peers and supervisors can help graduate students develop an identity.

Within the domain of sport pedagogy and psychology at a Canadian university, Betram et al. (2014) initiated a CoP to provide a learning space for graduate students to increase their academic skills of writing, critical thinking and research. Participants engaged in academic activities and shared ideas and experiences related to academia including discussions of members' current research projects and manuscripts as well as articles and chapters related to their research. Members also received information about conferences, potential grants and publications, and new students were provided with information about resources or processes on campus. A focus group followed by individual interviews reported that participants gained useful insight, strategies and resources that could not be attained without attending a $\mathrm{CoP}$ and stated that their involvement in a $\mathrm{CoP}$ helped them learn and cocreate knowledge related to relevant topics (Bertram et al., 2014). The researchers categorized the value of the a $\mathrm{CoP}$ as immediate, potential, applied, realized and reframing. The immediate value was receiving feedback from peers and professors in relation to their work and exposing members to new ideas, skills and strategies in relation to research and publication, which could potentially lead to academic success. Applied value was developing relationships and gaining experiences that could be applied to other situations and contexts. Realized value reflected members' increased skills, productivity, critical thinking and confidence in expressing their opinions and the "reframing value" of participating in a $\mathrm{CoP}$ was that members reexamined their perspectives and understandings of themselves and their world (Bertram et al., 2014). 


\section{Areas for improvements}

In our study, not all aspects of the $\mathrm{CoP}$ meetings were perceived to be useful, and participants shared ideas about how a CoP can better support social interactions and knowledge exchange for academic success. Participants expressed the need for greater frequency of $\mathrm{CoP}$ meetings (biweekly as opposed to monthly meetings), a mix of formal and informal learning opportunities, a social structure that facilitates interactions and relationships and an online repertoire of resources to guide their academic journey. Having more resources and meetings was particularly important at the beginning of the academic term when students are in transition and for students who are adjusting to a new social and learning environment. Wenger et al. (2002) suggest that to optimize the function of a $\mathrm{CoP}$, it is necessary to have boundaries for behaviors, so members can decide what and how to share their ideas and a set of resources that include information, experiences and ways of addressing problems.

We also found some participants felt a lack of connection and sense of community with other graduate students. In addition, some participants expressed frustration with the behaviors of certain members, a circumstance that was reflected in a study about a sevenmonth $\mathrm{CoP}$ with public health nutritionists $(n=12)$ working with remote Indigenous community stores across Australia (Holden et al., 2015). Through the $\mathrm{CoP}$, members aimed to develop the competencies and skills to support consumption of nutritious food within an Indigenous community. Members valued the resources and discussions and reported a sense of belonging and support, confidence and improved problem-solving (Holden et al., 2015). However, consistent with our finding, some members reported tension and challenges that included dominating discussions, lack of trust by some participants and failure of disclosing information or stories.

Wenger et al. (2002) suggests that the leaders or facilitators have a critical role in the success or failure of a group. However, it is less clear how a $\mathrm{CoP}$ facilitator should operate to foster a social structure for the group's success. For organized CoPs, we suggest establishing ground rules and expectations with members at the beginning and throughout the meetings to help foster a sense of respect and sharing between members. We suggest forming an online platform to enhance communication and connection. We also suggest that members identify their intention for participation to ensure they have a good understanding of what the $\mathrm{CoP}$ aims to accomplish. For example, we found that some of the participants in our study came to the sessions only to socialize. While social interaction is an important element of $\mathrm{CoP}$ that helps members develop knowledge, competencies and gain a sense of belonging, it is not meant to be a socializing event. $\mathrm{CoP}$ is established to accomplish other goals such as knowledge and skills creation and identity development. Therefore, we recommend student members lead some of the learning activities and facilitate some of the formal discussions. For sustainability, we also suggest engagement of senior leaders of the university to ensure the required resources such as funding and space (Reaburn and McDonald, 2017). Culver and Bertram (2017) encouraged CoPs in higher education to be conducted with faculty members and students with diverse background to help share different perspectives, ideas, attitudes and challenges for enhanced experiences (Culver and Bertram, 2017).

Social cognitive theory includes personal factors such as preconceptions, goals, motivations, sense of efficacy, attribution and self-regulation as important for influencing individuals' participation and engagement in learning activities such as CoPs. However, environmental factors such as those described in Bandura's triadic reciprocal determinism also have an effect on personal factors and learning. To help address differences in personalities (motivation, sense of efficacy and value) and improve participation in CoPs, we recommend focusing on environmental factors that are modifiable in university settings such as providing opportunities for socialization, connectedness and belonging and 
HEED

15,2

148

allowing graduate students, to conduct, lead and facilitate $\mathrm{CoP}$ sessions. Resources and knowledge can be provided in formal presentations from faculty members as guest speakers; however, findings from our study reveal that graduate students would benefit more from sessions that are managed and run by graduate students themselves who are more familiar with the concerns and needs. Student-led CoPs will help eliminate power dynamics that often exist between faculty members and students and can create comfortable, confidential and safe environments for graduate students to voice their concerns and share their experiences. To help provide a sense of belonging for international students, we suggest that an international graduate student who has completed or has almost completed a program would be an ideal colead and facilitator of a CoP. Participants in our study recommended that CoPs for graduate students include both formal and informal activities to accommodate different personalities and learning styles. We are currently using these approaches with our virtual $\mathrm{CoP}$ in the midst of the COVID-19 pandemic to accommodate different personalities, needs, motivations and values and have been successful in attracting a large group of local and international graduate students in Nursing and Rehabilitation Sciences.

As the premises of CoPs are bringing together people with shared concerns, practices or interests, people who identify with the goals of a $\mathrm{CoP}$ will typically attend. Therefore, posters and announcements for a graduate student $\mathrm{CoP}$ should provide clear and concise information about the strategies, goals and benefits of the CoP. Targeting different personal goals and values can enhance participation. Some of the ways that the goals of a $\mathrm{CoP}$ can be disseminated is by having graduate students who have benefited from participating in a CoP attend formal classes or groups at the university to explain the objectives and emphasize the benefits and opportunities for learning, socializing, identity building and knowledge sharing.

\section{Study limitations and future research directions}

While this is a small descriptive exploratory study, findings are useful to understand graduate students' experiences with a $\mathrm{CoP}$ and lead the way for future research. In our study, the research assistant's membership in the $\mathrm{CoP}$ prior to conducting the interviews was both a strength through familiarity of the $\mathrm{CoP}$ context and a weakness through the potential for social response bias from participants.

We suggest further studies are needed to understand the academic context that impacts graduate students' social and physical health in addition to their academic outcomes. In particular, larger studies are required to describe the diverse needs of international students, so CoPs can be developed to address the additional challenges they face at graduate school in a foreign country. Robust intervention studies are also required to determine the impact of a $\mathrm{CoP}$ on social interactions, knowledge development and academic success. Based on our study findings and other $\mathrm{CoP}$ research, we are developing a new $\mathrm{CoP}$ to address the needs of graduate students in the Faculty of Health Sciences at our university. We will be adapting the $\mathrm{CoP}$ to the current context that includes a virtual platform during the COVID-19 pandemic and will include content specific for international students. We aim to support graduate students and faculty members come together for mutual learning and sharing to accomplish their individual and group goals and optimal outcomes for members.

\section{Conclusion}

Educational institutions have a fundamental obligation to provide a learning environment that promotes well-being, productivity and academic success for graduate students. A CoP offers a supportive forum for graduate students to engage in positive social interactions, 
knowledge sharing and learning. This study revealed numerous ways a $\mathrm{CoP}$ can benefit graduate students, such as having formal and informal interaction, establishing a common ground for sharing and creating a social structure that enhances belonging and learning. We also highlighted some of the challenges along the way. Incorporating graduate students' ideas into a $\mathrm{CoP}$ can create a supportive environment to better meet their needs for academic success. In our next CoP, we plan to build on these findings and adapt it to the COVID-19 pandemic and beyond.

\section{References}

Ammigan, R. and Jones, E. (2018), "Improving the student experience: learning from a comparative study of international student satisfaction", Journal of Studies in International Education, Vol. 22 No. 4, pp. 283-301, doi: 10.1177/1028315318773137.

Arkoudis, S., Dollinger, M., Baik, C. and Patience, A. (2018), "International students' experience in Australian higher education: can we do better?", Higher Education, Vol. 77, pp. 799-813, doi: 10. 1007/s10734-018-0302-x.

Bandura, A. (1999), “A social cognitive theory of personality”, in Pervin, L. and John, O. (Eds), Hnadbook of Personality, Guildford Publications, New York, pp. 154-196.

Bertram, R., Paquette, K., Duarte, T. and Culver, D. (2014), “Assessing the value created through participating in a graduate studies community of practice", Transformative Dialogues: Teaching and Learning Journal, Vol. 7 No. 1, pp. 1-14.

Blanchard, V. (2018), "Doctoral program completion: grit, goal-setting, social support. (Publication No. 2130847133)", [Doctoral dissertation, Seton Hall University], ProQuest Dissertations and Theses Global.

Brown, K., Anderson-Johnson, P. and McPherson, A.N. (2016), "Academic-related stress among graduate students in nursing in a Jamaican school of nursing", Nurse Education in Practice, Vol. 20, pp. 117-124, doi: 10.1016/j.nepr.2016.08.004.

Cater-Steel, A., McDonald, J., Albion, P. and Redmond, P. (2017), "Sustaining the momentum: a crossinstitutional community of practice for research supervisors", in McDonald, J. and Carter-Steel, A. (Ed.), Implementing Communities of Practice in Higher Education, Springer, Singapore, pp. 3-17, doi: 10.1007/978-981-10-2866-31.

Cepanec, D., Humphries, A., Rieger, K.L., Marshall, S., Londono, Y. and Clarke, D. (2016), "Building graduate student capacity as future researchers through a research and training award program", Journal of Nursing Education, Vol. 55 No. 5, pp. 284-287, doi: 10.3928/0148483420160414-08.

Culver, D.M. and Bertram, R. (2017), "Learning value and identity formation: social learning and the graduate studies experience", in McDonald, J. and Cater-Steel, A. (Eds), Implementing Communities of Practice in Higher Education, Springer, Singapore, pp. 347-372.

Davis, J. (2006), "The importance of the community of practice in identity development", The Internet Journal of Allied Health Sciences and Practice, Vol. 4 No. 3, pp. 1-8.

deChambeau, A.L. (2014), "Supported student success: communities of practice in higher education", dissertation, Prescott College, Arizona.

DeClou, L. (2016), "Who stays and for how long: examining attrition in Canadian graduate programs", Canadian Journal of Higher Education, Vol. 46 No. 4, pp. 174-198.

Evans, T.M., Bira, L., Gastelum, J.B., Weiss, L.T. and Vanderford, N.L. (2018), "Evidence for a mental health crisis in graduate education", Nature Biotechnology, Vol. 36 No. 3, pp. 282-284, doi: 10. 1038/nbt.4089.

Fenge, L.A. (2012), "Enhancing the doctoral journey: the role of group supervision in supporting collaborative learning and creativity", Studies in Higher Education, Vol. 37 No. 4, pp. 401-414, doi: 10.1080/03075079.2010.520697. 
HEED 15,2
Government of Canada (2020), "Building on success: international education strategy 2019-2024", available at: https:/www.international.gc.ca/education/strategy-2019-2024-strategie.aspx? lang=eng (accessed 20 September 2020).

Holden, S., Ferguson, M., Brimblecombe, J. and Palermo, C. (2015), "Can a community of practice equip public health nutritionists to work with remote retail to improve the food supply?", Rural and Remote Health, Vol. 15 No. 4, pp. 1-11.

Ickes, M.J., Brown, J., Reeves, B. and Martin, P. (2015), "Differences between undergraduate and graduate students in stress and coping strategies", Californian Journal of Health Promotion, Vol. 13 No. 1, pp. 13-25, doi: 10.32398/cjhp.v13i1.1810.

Iverson, J.O. (2010), "Knowledge, belonging, and communities of practice", in Canary, H.E. and McPhee, R.D. (Eds), Communication and Organizational Knowledge: Contemporary Issues for Theory and Practice, Routledge, pp. 45-52.

Karkar-Esperat, T.M. (2018), "International graduate students' challenges and learning experiences in online classes", Journal of International Students, Vol. 8 No. 4, pp. 1722-1735.

Li, L.C., Grimshaw, J.M., Nielsen, C., Judd, M., Coyte, P.C. and Graham, I.D. (2009), "Evolution of Wenger's concept of community of practice”, Implementation Science, Vol. 4 No. 11, pp. 1-8, doi: 10.1186/1748-5908-4-11.

MacGillivray, A.E. (2017), "Social learning in higher education: a clash of cultures?", in McDonald, J. and Cater-Steel, A. (Eds), Implementing Communities of Practice in Higher Education, Springer, Singapore, pp. 27-45.

Mazurek Melnyk, B., Slevin, C., Militello, L., Hoying, J., Teall, A. and McGovern, C. (2016), "Physical health, lifestyle beliefs and behaviors, and mental health of entering graduate health professional students: evidence to support screening and early intervention", Journal of the American Association of Nurse Practitioners, Vol. 28 No. 4, pp. 204-211, doi: 10.1002/23276924.12350.

McDonald, J. and Cater-Steel, A. (Eds) (2016), Implementing Communities of Practice in Higher Education: Dreamers and Schemer, Springer, Singapore.

Merola, R.H., Coelen, R.J. and Hofman, W.H.A. (2019), "The role of integration in understanding differences in satisfaction among Chinese, Indian, and south Korean international students", Journal of Studies in International Education, Vol. 23 No. 5, pp. 535-553, doi: 10.1177/ 1028315319861355.

Palmer, P. (2002), “The quest for community in higher education”, in McDonald, W.M. (Ed.), Creating Campus Community: In Search of Ernest Boyer's Legacy, John Wiley \& Sons, San Francisco, pp. 179-192.

Peltonen, J.A., Vekkaila, J., Rautio, P., Havernen, K. and Pyhältö, K. (2017), “Doctoral students' social support profiles and their related burnout, dropout intentions and time to candidacy", International Journal of Doctoral Studies, Vol. 12, pp. 157-173, doi: 10.28945/3792.

Pyrko, I., Dörfler, V. and Eden, C. (2017), “Thinking together: what makes communities of practice work?", Human Relations, Vol. 70 No. 4, pp. 389-409.

Ray, M.E., Coon, J.M., Al-Jumaili, A.A. and Fullerton, M. (2019), "Quantitative and qualitative factors associated with social isolation among graduate and professional Hhalth science students", American Journal of Pharmaceutical Education, Vol. 83 No. 7, pp. 69-83, doi: 10.5688/ajpe6983.

Reaburn, P. and McDonald, J. (2017), "Creating and facilitating communities of practice in higher education: theory to practice in a regional Australian university", in McDonald, J. and CaterSteel, A. (Eds), Implementing Communities of Practice in Higher Education, Springer: Singapore, pp. 121-150, doi: 10.1007/978-981-10-2879-3_6.

Rigler, K.L., Bowlin, L.K., Sweat, K., Watts, S. and Throne, R. (2017), "Agency, socialization, and support: a critical review of doctoral student attrition”, Paper Presented at the 3rd International Conference on Doctoral Education, University of Central Florida, available at: https://files.eric. ed.gov/fulltext/ED580853.pdf (accessed 29 August 2020). 
Sandelowski, M. (2000), "Focus on research methods-whatever happened to qualitative description?", Research in Nursing and Health, Vol. 23 No. 4, pp. 334-340.

Statistics Canada (2016), "Study: international students in canadian universities, 2004/2005 to 2013/ 2014", available at: http://www.statcan.gc.ca/daily-quotidien/161020/dq161020e-eng.htm (accessed 20 August 2020).

Wenger, E., McDermott, R.A. and Snyder, W. (2002), Cultivating Communities of Practice: A Guide to Managing Knowledge, Harvard Business School Press, Massachusetts, Boston.

Wenger-Trayner, E. and Wenger-Trayner, B. (2015), "Communities of practice: a brief introduction", available at: http://hdl.handle.net/1794/11736 (accessed 25 August 2020).

Wu, H.-P., Garza, E. and Guzman, N. (2015), "International student's challenge and adjustment to college”, Education Research International, Vol. 2015, Article ID 202753, 9 pages, doi: 10.1155/ 2015/202753.

\section{Corresponding author}

Liquaa Wazni can be contacted at: 1wazn023@uottawa.ca

For instructions on how to order reprints of this article, please visit our website:

www.emeraldgrouppublishing.com/licensing/reprints.htm

Or contact us for further details: permissions@emeraldinsight.com 